\title{
EFFECT OF SOME ENVIRONMENTAL PARAMETERS ON CROSSING PROCESS OF TARGET SNAILS TO SCHISTOSOMA MANSONI INFECTION
}

Abdel - Hamid Z. Abdel - Hamid ${ }^{1}$, Samia M. Abd El-Wahab ${ }^{2}$,
Mona M. El - Tonsy ${ }^{2}$ and Rehab M. Abdel - Megeed From Medicinal Chemistry Department, National Research Center ${ }^{1}$ and Zoology Department, Faculty of Science ${ }^{2}, \mathrm{Al}$ - Azhar University for Girls , Cairo, Egypt.

Keywords: Schistosoma mansoni, Biomphalaria, biological control, environmental parameters.

\section{ABSTRACT}

The biological control of the snails intermediate hosts of Schistosoma the control of schistosomiasis, one strategy is based on the premise that resistant snails to parasite infection could be used as biological competition agents to replace existing susceptible snails in endemic areas. Therefore, the current studv was designed to investigatexthe influence of environmental factors on copulation behaviour of Biomphalaria snails under various laboratory conditions \%. These factors are : light, darkness, starvation, $\mathrm{pH}$ and association with non- target snail species order to obtain information on the ecological conditions for reproduction of the resistant species.

The data obtained showed that, copulation behavior was enhanced by different environmental factors and revealed the best modular system for snail reproduction. It was-atso noticed that, non-target snail species or the resistant snails affect crossing among the target snails . Moreover, resistant snails recorded more tolerănce against abnormal environmental conditions.

\section{INTRODUCTION}

Outcrossing and self - fertilization are common modes of reproduction in pulmonate gastropods (Jarne \& Stadler , 1995 ). Biomphalaria snails are simultaneous hermaphrodite with ability of selffertilization, however, in the presence of partner ( when paired ) cross - 
Abdel - Hamid Z. Abdel - Hamid et al.

fertilization is preferred ( Vidigal et al., 1994 \& 1998 a \& b ). Selfing snails often have a lower fecundity than cross - fertilizing snails ( Bayomy \& Joose, 1987 ) .

Biological methods for control of freshwater snails were reviewed by Madsen (1992 ), who concluded that more emphasis should be put on searching for pathogens or microparasites as agent for control that can affect directly or indirectly on the intermediate snail hosts. These include bacteria , fungi , Protozoa , Amphibia and fish ( Slootweg et al., 1993 ), other competitor snails ( Abdel - Hamid \& Ali , 1998 ) and Muschovy ducks ( Cairina maschata) (Ndlela \& Chimbari , 2000).

Although physical, chemical, and biological factors have a significant effect on population dynamics, temperature, water chemistry, current speed. light. shade, snail 's leeding and association among species are of particular importance in the natural history of planorbid snails (Brown, 1994). Walcer chemistry includes calcium concentration, total dissolved chemical elements and oxygen. The densities of all snail species appear very low in salt water, high in medium water and somewhat lower in hard water ( Beillle, 1981). The level of oxygen may have an important influence on distribution within habitats.

Certain environmental factors have pronounced effects on the susceptibility of snails to infection. For example, a decrease in the temperature has a substantial influence on the development of $S$. mansoni infection in B. glahrata (Coelho \& Bezerra, 2006 ). However, Richards ( 1984 ) suggested that, the susceptibility of snails to infection is a hereditary character. Unfavourable conditions, however, can be caused by dense floating vegetation, preventing snail from reaching the surface when there is a shortage of dissolved oxygen (Brown, 1994). Snail hosts for schistosomes were reported for several generations in almost total darkness ( Appleton, 1978 ). Shaded sites were unfavourable for Biomphalaria pfeifferi and shading by trees was suggested as a mean for controlling this snail. Dense shade beneath mats of floating vegetation is generally unfavourable for snails ( Nidifon \& Ukoli , 1989 ). Most aquatic habitats contain rich microflora which, together with decaying vegeTable matter, provide the snails diet and are probably important in conditioning the habitat ( Malek , 1958). Food in the habitat seemed to influence the reproduction of the snail hosts and their population dynamics. 


\section{MATERIAL AND METHODS}

Target and non-target snail species for Schistosoma infection ( Biomphalaria alexandrina, Biomphalaria glabrata , Lymnaea truncatula and Physa acuta) were obtained from the field ( Giza governorate , Egypt ). Five - liter glass aquaria were used in the experiment . To breed the snails, $500 \mathrm{ml}$ beakers and some crystallizing dishes were used. Snail conditioned water ( $\mathrm{SCW}$ ) was used in the aquaria and at weekly intervals, the aquaria were cleaned and their water changed. The snails were fed on fresh lettuce leaves supplemented with tetramin ( fish food ). After careful selection on the basis of health, size and age, methods of separating schistosome resistant and susceptible strains from both $B$. alexandrina and $B$. glabrala were performed according to the method described by Zanotti- Magalhaes et al. (1997).

Adult snails were exposed individually to 10 freshly hatched miracidia of $S$. mansoni-Egyptian strain obtained from Schistosome Biological Supply Project ( SBSP), ( Theodur Bilharz Rescarch Institute, Egypt) in vials containing $3 \mathrm{ml}$ water for $3-4$ hours . Each tested snail was returned and reared singly in a beaker containing $500 \mathrm{ml} \mathrm{SCW}$.

Snails were examined at 10 days post - exposure and checked for infection with a binocular microscope. Snails with developing sporocysts were transferted to another flask and kept for cercarial emergence for 10 weeks post - exposure. As described by Theron \& Coustau ( 2005 ), snails that became infected are considered susceptible hosts and those which are not infected are traditionally determined as resistant .

\section{Selfing / out crossing :}

- Both susceptible and resistant parent stocks of either $B$. alexandrina or $B$. glabrata snails were isolated and reared singly for self - fertilization These self - fertilized snails were used for breeding and for current studies as following:

Different developmental stages ; juvenile ( J ), adult ( Ad ) and senescent ( $\mathrm{Se}$ ) from either susceptible or resistant strains were obtained in successive generations by rearing snails singly each in $500 \mathrm{ml}$ plastic container containing SCW. On the other hand, crosses among adult and senescent snails were performed.

To confirm hybridization phenomenon within both $B$. alexandrina and $B$. glabrata, the following experiment was conducted. Four groups of snails each contains one $B$. alexandrina (either susceptible or resistant) and one $B$. glabrata (susceptible or resistant ) were left to live in pairs in 
clean plastic containers ( $500 \mathrm{ml}$ ). Crossing numbers and duration of each cross were recorded during 6 hours of pairing with $15 \mathrm{~min}$. interval. The experiments were repeated 5 times.

Effect of some environmental conditions on the snails reproduction: 1 - Effect of light and darkness:

a) Both $B$. alexandrina and B. glabrata, either susceptible or resistant were maintained individually for 24 hours in a clean plastic containers ( each of $250 \mathrm{ml}$ ) containing sew in order to acclimatize the snails to environmental conditions before starting laboratory experiments.

b ) The snails of each species and strain were divided into two groups: the first group was allowed to live in pairs under light, while the second one was put in darkness for 6 hours. Twenty four observations with intervals of 15 min. during 6 hours were recorded for each group and the number of crossing and the duration of each cross were recorded for each species, strain and stage.

\section{2 - Effect of starvation:}

The effect of starvation on reproduction of both susceptible and resistant within $B$. alexandrina and B. glabrata snails populations was examined according to the method described by Pinheiro et al. ( 2001 ).

The first group was fed on fresh lettuce leaves supplemented with tetramin (fish food) [ingredient statement: fish meat, shrimp meat, aquatic plants. oat flour yeast various vitamins, chlorophyll]. while the second one was starved for 24 hours .

\section{3 - Effect of pll :}

Adult stages of both $B$. alexandrina and B. glabrata snails were left to live in pairs under suiTable environmental conditions except $\mathrm{pH}$ levels.

Six pairs of the acclimatized experimental snails were maintained in clean plastic containers, each contains $500 \mathrm{ml}$ sew at different $\mathrm{pH}$ that ranged from $4-9$.

The numbers of crossing and duration of each cross were recorded with intervals of $15 \mathrm{~min}$. for $6 \mathrm{hrs}$. The experiment was repeated 3 times with exchanging the place of the containers.

4-Influence of non-target snail species on the ability of both $B$. alexandrina and $B$. glabrata to crossing:

Each pair of snails ( either B. alexandrina or B. glabrata) was left to live in clean plastic containcr containing 500 sew under the suiTable environmental conditions. Physa acuta and L. truncalula (as non- target snails to Schistosoma parasite) were added to live in the containers 
together with the target snail of $B$. alexandrina or B. glabrata. Numbers of crossing and the duration of each cross were recorded for $6 \mathrm{hrs}$. with intervals of $15 \mathrm{~min}$.

Statistical analysis

Statistical analysis of results was carried out using analysis of variance ( ANOVA) according to Campbell ( 1989 ).

\section{RESULTS}

Factors affecting the crossing process :

\section{1 - Effect of light and darkness :}

The longest total crossing period was recorded under lighted conditions in groups of both B. alexandrina and B. glabrata as shown in Tables $(1 \& 2)$. The resistant individuals at adult stage of each group has longest total crossing period which recorded 64.5 and $83.3 \mathrm{~min}$. for $B$. alexandrina and $B$. glabrata respectively .However, the susceptible forms at senescent stage had the shortest total crossing period which recorded 10.4 and $14.7 \mathrm{~min}$. of $B$. alexandrina and $B$. glabrata respectively .

It was also observed that , $B$. glabrata was more tolerant to darkness than $B$. alexandrina, since there was no recorded crossing period in most $B$. alexandrina groups in the darkness .

The longest crossing period in darkeness was found in adult groups of B. glabrata of resistant individuals, where it recorded 24.1 min. and the shortest was found in senescent susceptible ones which recorded $0.57 \mathrm{~min}$. .

\section{2 - Effect of starvation :}

From Tables ( $3 \& 4$ ), the total crossing period in the feeding groups of both $B$. alexandrina and B. glabrata was longer than in the corresponding starved group .

It was also noticed that, adult resistant snails had the longest total crossing period in all tested groups ( $89.2 \& 62.1 \mathrm{~min}$. ). In contrast, the senescent susceptible ones had the shortest total crossing period ( 11.8 \& $22.0 \mathrm{~min}$. ) . Data listed showed that, the resistant individuals of both snail species were more tolerant to starvation than susceptible ones. Adult snails were also more tolerant to starvation than senescent stages ( 19.8 \& $0.65 \mathrm{~min}$. .).

From Tables ( $1,2,3 \& 4$ ), it was observed that the total crossing period was affected by snail species, where in case of $B$. 
glabrata, the total crossing period was longer than those corresponding in $B$. alexandrina. The snail type can also affect total crossing period, where total crossing periods in all resistant strains within the two snail species were longer than those corresponding in susceptible ones. It was also noticed that, the total crossing periods were affected by snail age , where crossing periods in adult groups were longer than those corresponding in senescent groups.

Furthermore, the results showed that tolerance of $B$. glabrata to abnormal conditions ( e.g. darkness - starvation ) was higher than those in B. alexandrina .

3- Effect of pH :

In Table $5, B$. alexandrina snails showed the longest crossing period within 6 hours at $\mathrm{pH} 7$, since they recorded $64.8 \mathrm{~min}$. for susceptible progeny and $84.8 \mathrm{~min}$. for resistant ones. Total crossing period recorded an obvious decrease at lower $\mathrm{pH}$ as well as at $\mathrm{pH} 8$ then it reverted to slight increase at $\mathrm{pH} 9$.

Table 6 illustrates the effect of different $\mathrm{pH}$ on $B$. glabrata crossing rate. The longest total crossing period was recorded around $\mathrm{pH} 6$ for susceptible snails and at $\mathrm{pH} 7$ for resistant ones. Remarkable decrease was also observed in acidic media . In alkaline media, the total crossing period tended to decrease in $\mathrm{pH} 8$ but it reverted to increase slightly at $\mathrm{pH}$ 9 for resistant snails and largely for susceptible one.

4 - Target / non-target snail compatibility:

Tables 7 and 8 demonstrate the crossing process of $B$. alexandrina and $B$. glabrata in snail modular system ( SMS ) containing both $P$. acuta and L. truncatula as non-target snails to Schistosoma infection .

The results showed a decrease in total crossing period of target snail species, while a remarkable decrease was observed in the presence of non-target species compared with the control.

In the presence of the non-target snails of $P$. acuta in SMS, resistant individuals of both target snail species ( $B$. alexandrina \& $B$. glabrata) recorded more total crossing period than susceptible ones . 5 - Hybridization between $B$. alexandrina and $B$. glabrata :

The recorded data showed decrease in crossing period in all the tested gioups than the corresponding control groups and the crossing ability between the two Biomphalaria species was less than those corresponding within individuals of the same species .

The data also showed that, crossing between different Biomphalaria species is affected by snail type, where the crossing period 
within resistant individuals was more than those in susceptible ones ( $48.18 \& 13.78 \mathrm{~min}$ ) as described in Table ( 9 ).

\section{DISCUSSION}

The precise distribution of snails is considered of potential importance, while understanding of factors regulating snail distribution could be valuable for control purposes. So, the present study provides further evidence that the distribution of these snails is a result of more complex interaction of different factors such as nutrition, light and darkness, $\mathrm{pH}$ and association with other snail species that is reflected on snail mating system .

Vernon ( 1995 ) suggested that, absence of social facilitation may reduce the reproductive output of $B$. glabrata. This result agrees with the present data about the effect of changing natural habitat on crossing process, where a significant decrease was reported in copulation behavior by modifying snail habitat .

Furthermore, Biomphalaria snails can copulate at high rate in $\mathrm{pH}$ $6-7$ and the crossing rate decreased at higher or lower limits. This agrees with Donnelly et al. ( 1984 ) who observed prevention of establishment of intermediate hosts for schistosomes in water at high salinity.

In addition, the starvation of snails showed lower crossing rate compared with the fed ones. Similarly, O'keefe ( 1985 ) concluded that poor food quality appeared to limit populations of $B$. globosus during most of the year. In contrast, Vianey - Liaud and Dussart ( 1994 ) found that after all periods of starvation and desiccation, albino snail parents were still producing significant numbers of pigmented offsprings, suggesting preferential cross - fertilization with B. glabrata using stored allosperm .

On the other hand, Biomphalaria snails prefer to cross at higher rate than those associated with other non-target freshwater snails. This result describes the occurrence of two or more species in natural habitat with each other and negative association as reported by Thomas and Tait ( 1984 ). Furthermore, our experimental study shows high decrease in crossing response between $B$. alexandrina and $B$. glabrata, whereas $P$. acuta and $L$. truncatula in the same water medium with $B$. alexandrina and B. glabrata suppressed their rate of egg production .

Therefore, the snail species affects the crossing process, where its duration time was larger in $B$. glabrata than those corresponding in $B$. 
alexandrina. Moreover, the snail type affects the crossing process, where total crossing periods in all resistant groups were larger than those corresponding in all susceptible ones. Furthermore, the snail age of the same species and strain affected the crossing process, where all adult groups recorded higher crossing time than the corresponding senescent ones . These observations confirm those of Coulellec - Vreto et al. (1997) who reported that the mating system of such species has been proven to be highly variable either between populations or between families within populations ( Ritland \& Ganders , 1985 ; Willis , 1993 ).

It was also found that the snails preferred to cross at moderately lighted habitat. This agrees with Brown (1994) who reported that shaded sites are unfavourable for $B$. pfeifferi and shading by trees was suggested as a means for controlling these snails. So, from our results, we can suggest the best modular system for snail breeding, which enhance the egg production and distribution of the intermediate host snail .

Furthermore, the current study indicated that hybridization could occur between B. alexardrina and B. glabrata as regarded by Yousif et al. ( 1998 ) who reported that hybrid snails were found naturally and participated in schistosomiasis transmission in Egypt .In contrast, Lotfy et al. ( 2005 ) reported that there was no evidence of the presence of hybridization of $B$. alexandrina with $B$. glabrata in the Nile Delta in Egypt .

\section{REFERENCES}

Abdel-Hamid, A. Z. and Ali, S. M. (1993). Hirudo medicinalis as a potent agent for biological control of intermediate hosts of African Schistosome species . Egypt . J. Pharm. Sci., 39: 211-224.

Abdel-Hamid, A. Z. ; Rawi, S. and Arafa, A. S. ( 2006 ). Identification of the genetic marker associated with the resistance to Schistosoma mansoni infection using RAPD-PCR analysis . Mem. Inst. Oswaldo Cruz., $101: 35-41$.

Appleton, C. C. (1978). Review of literature on biotic and abiotic factors influencing the distribution and life cycles of bilharziasis intermediate host snails. Malacol. Rev., 11: 1-25. 
Bayomy, M. F. F. and Joosse, J. (1987). The effect of isolation, grouping and population density on fecundity of Bulinus truncates. Int. J. Jnvertebr. Reprod. Dev., 12: 319-330.

Beadle, L. C. (1981). The inland waters of tropical Africa. $2^{\text {nd }}$ Ed. London. New York. Longman.

Brown, D. S. (1994). Freshwater snails of Africa and their medical importance, $2^{\text {nd }}$ Edition, London; Taylor and Francis.

Campbell, R. C. (1989). Statistics for Biologists. $3^{\text {td }}$ ed., (R. C. Campbell, ed). Cambridge University Press, Cambridge New York, Melbourne, Sydney.

Coelho, J. R. and Bezerra, F. S. M. ( 2006 ). The effects of temperature change on the infection rate of Biomphataria glabrata with Schistosoma mansoni . Mem. Insi. Oswaldo ('ruz., Rio. De janeiro, $10: 223-224$.

Coulellec-Vreto, M. A. ; Madec, L. and Guiller, A. (1997). Selfing and biparental inbreeding: a mating system analysis in Lymnaea peregra. Heredily. 79: 277.285.

Donnelly, F. A. ; Appleton, C. C. ; Begg, (i. W. and Schutte, C. H. J. (1984). Bilharzia transmission in Natal's estuaries and logons : fact or fiction? South African . Journal of Science, 80: 455-460.

Jarne, P. and Stadler, T. (1995). Population genetic structure and mating system evolution in freshwater pulmonates. Experientia, 51:482-497.

Lotfy, W. M. ; Dejong, R. J. ; Abdel-Kader, A. and Loker, E. S. ( 2005 ). A molecular survey of Biomphalaria in Egypt : Is B. glabrata present ?. Am. J. Trop. Med. Hyg., $73: 131-139$.

Madsen, H. (1992). Food selection by freshwater snails in the Gezira irrigatiion canals, Sudan . Hydrobiol., 228: 203-217.

Malek, E. A. (1958). Factors conditioning the habitat of bilhariziasis intermediate hosts of the family Planorbidae. Bull. WHO,18: $785-818$. 
Ndifon, G. T. and Ukoli, F. M. A. (1989). Ecology of freshwater snails in south western Nigeria, I : Distribution and habitat preferences. Hydrobiol., 171: 231-253.

Ndlela, B. and Chimbari, M. J. (2000). A preliminary assessment of the potential of the Muschovy duck (Carina maschata) as a biocontrol agent of schistosomiasis intermediate host snails. Cent. Afr. J. med., $46: 271-275$.

O'keefe, J. H. (1985). Population biology of the freshwater snail Bulinus globosus on the Kenya Coast. 2. Feeding and density effects on population paramelers . J. Appl. licol., 22: 85-90

Pinheiro, J.; Gomes, E. M. and Changes, G. M. (2001 ). Aminotransferasc activity in the haemolymph of Bradybaera similaris (Gastropoda . Xanthonychidac ) under starvation. Mem. Inst. ()swaldo Cruz.. 96: $1161-1164$.

Richards C. S. ( 1984 ). Influence of snail age on genetic variations in susceptibility of Biomphalaris glabrats for infection with Schistosomu mumuni. Malacology. $25: 493$ - 502.

Rilland, K. and (ianders, F. R (1985). Variation in the mating system of Bide'ns menzicisit (Asteraceae) in relation to population substructure. Heledity . . 25: 235-244.

Slootweg, R. ; Malek, E. A. and McCullough, F. S. (1993). The biological control of snail intermediate hosts of schistosomiasis by fish. Rev. Fish. Biol. Fish. , 3: 33-56.

Theron, A. and Coustau, C. ( 2005 ). Are Biomphalaria snails resistant to Schistosoma mansoni ? . J. Helminthol. , $79: 187$ - 191 .

Thomas, J. D. and Tait, A. I. (1984). Control of the snail hosts of schistosomiasis by environmental manipulation: $A$ field and lahoratory appraisal in the Ibadan area, Nigeria. Phil. Trans. Roy. Siri.. Lond. , B , 305: 201-253.

Vernon . J. G. ( 1995 ). Low reproductive output of isolated, self fertilizing snails : inbreeding depression or absence of social facilitation ? Proc. R. Soc. Lond. B., $259: 131-136$. 


\section{EFFECT OF ENVIRONMENTAL PARAMETERS ON CROSSING 11 PROCESS OF TARGET SNAILS TO S. MANSONI INFECTION}

Vianey - Liaud, M. and Dussart, G. ( 1994 ). Starvation, desiccation and use of allosperm in the hermaphrodite freshwater snail Biomphalaria glabrata (Gastropoda : Pulmonata ). J. Moll. Stud. , $60: 255-262$

Vidigal, T. H. ; Dias, N. E. ; Spatz, L. ; Nunes, D. N. ; Pires, E. R. ; Simpson, A. J. and Carvalho, O. S. (1998a). Genetic variability and identification of the intermediate snail hosts of Schistosoma mansoni. Mem. Inst. Oswaldo. Cruz., 93: 103-110.

Vidigal, T. H. ; Neto, E. D. ; Carvalho, O. S. and Simpson, A. J. G. (1994). Biomphalaria glabrata : Extensive genetic variation in Brazilian isolates revealed by random amplified polymorphic DNA analysis. Exp. Parasitol., 79: 187-194.

Vidigal, T. H. ; Spatz, L. ; Nunes, D. N. ; Simpson. A. J. G. ; Carvalho, O. S. and Neto, E. D. (1998b). Biompholaria sp.: identification of the intermediate snail hosts of Schistosoma mansoni by polymerase chain reaction amplification and restriction enzyme digestion of the ribosomal RNA gene intergenic spacer. Exp. Parasitol., 89: 180-187.

Willis, J. H. (1993). Partial self-fertilization and inbreeding depression in two populations of Mimulus guttatus . Heredity . 21: 145-154.

Yousif, F. F. ; lbrahim, A. and El-Bardicy, S. N. (1998). Compatibility of Biomphalaria alexandrina, Biomphalaria glabrata and a hybrid of both to seven strains of Schistosoma mansoni from Egypt . J. Egypt. Soc. Parasitol. , 28 : 863-881.

Zanotti-Magalhaes, E. M. ; Magalhaes, L. A. and Carvalho, J. R. (1997). Relacao intre pathogencidade do Schistosoma mansoni em camundongos e a susceptibilidade do molusco vector. IV. Infecciosidade dos miracidios. Rev. Saude Puplica, 29: 265-270 cited from Abdel-Hamid et al. (2006). 


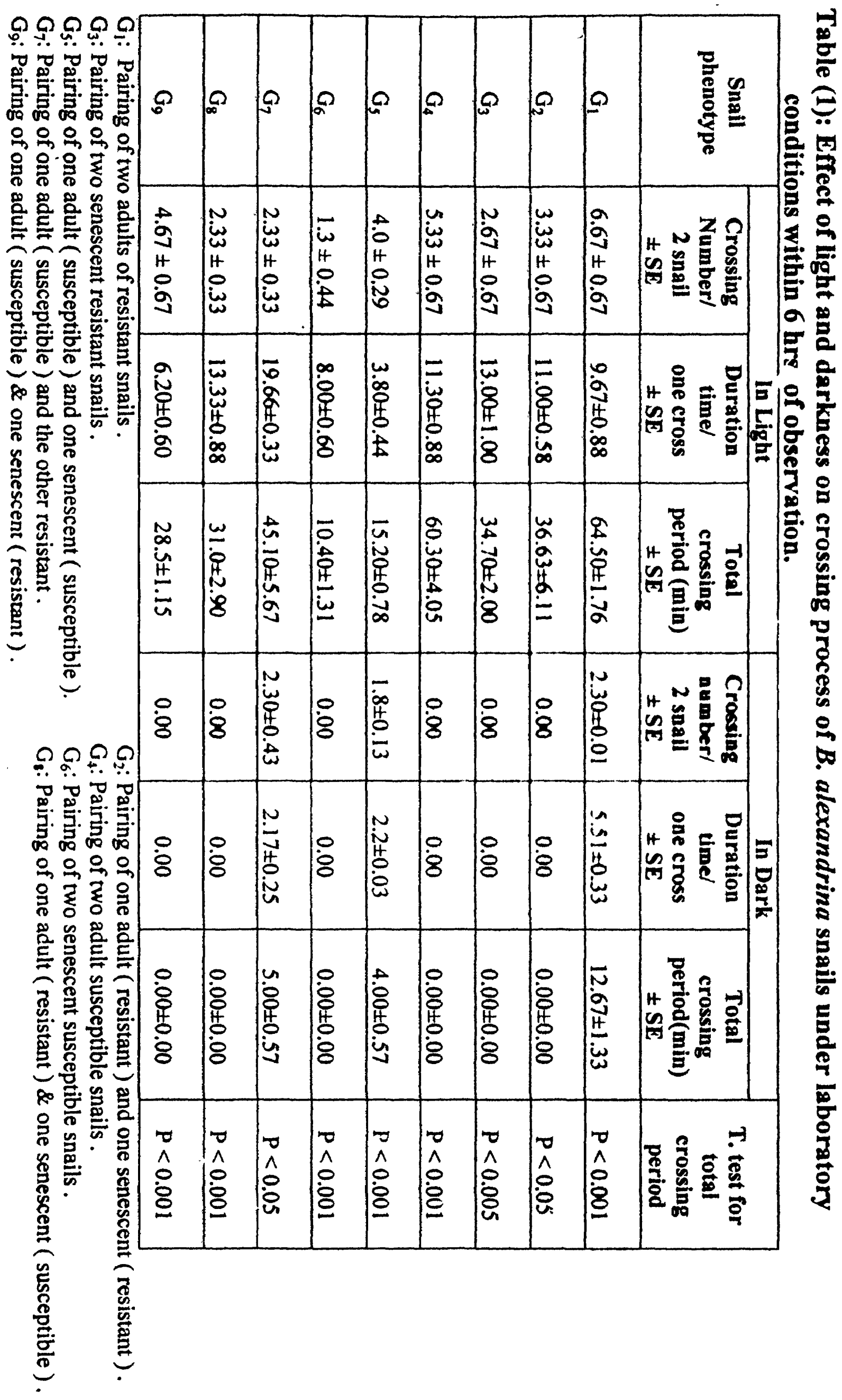




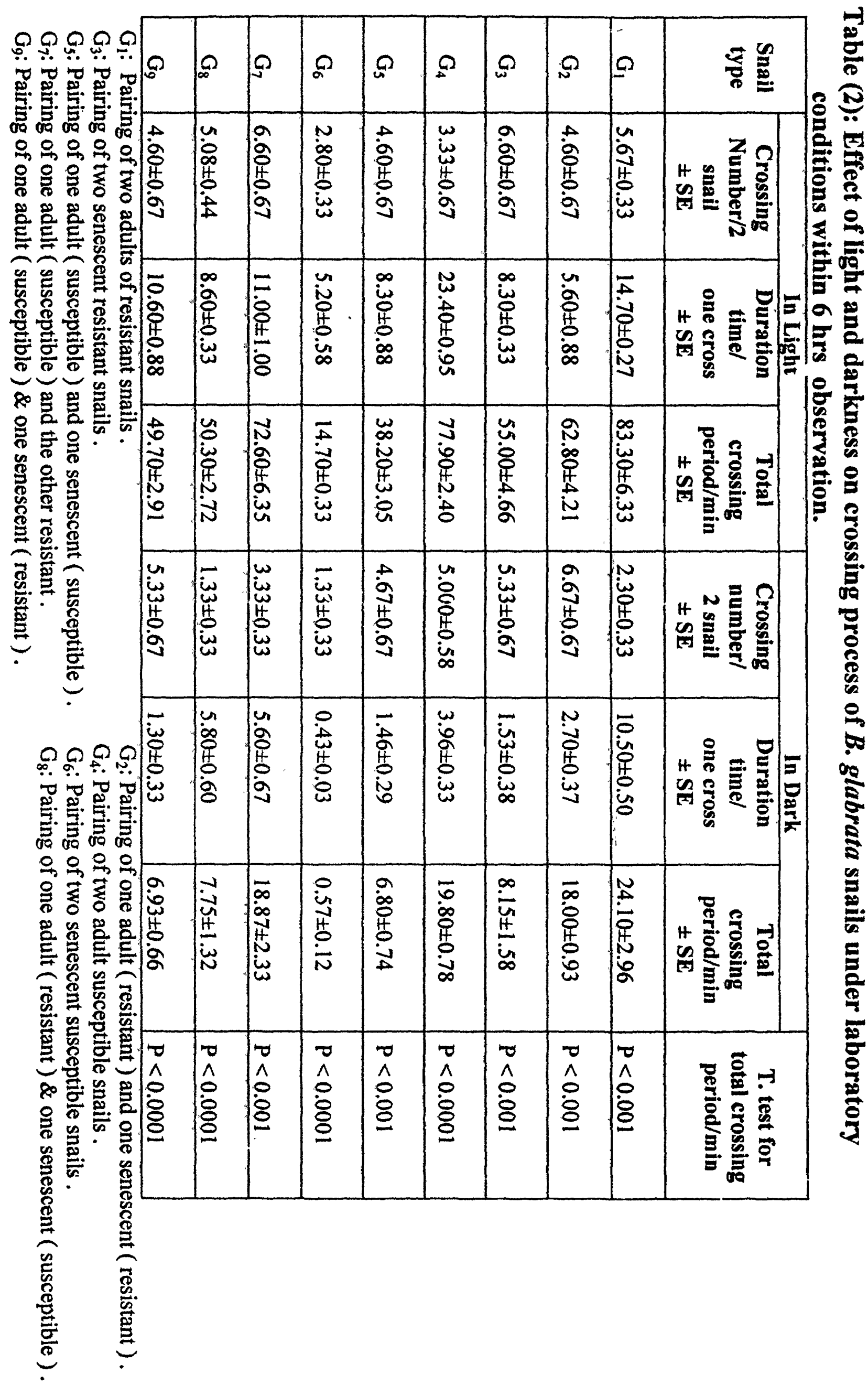




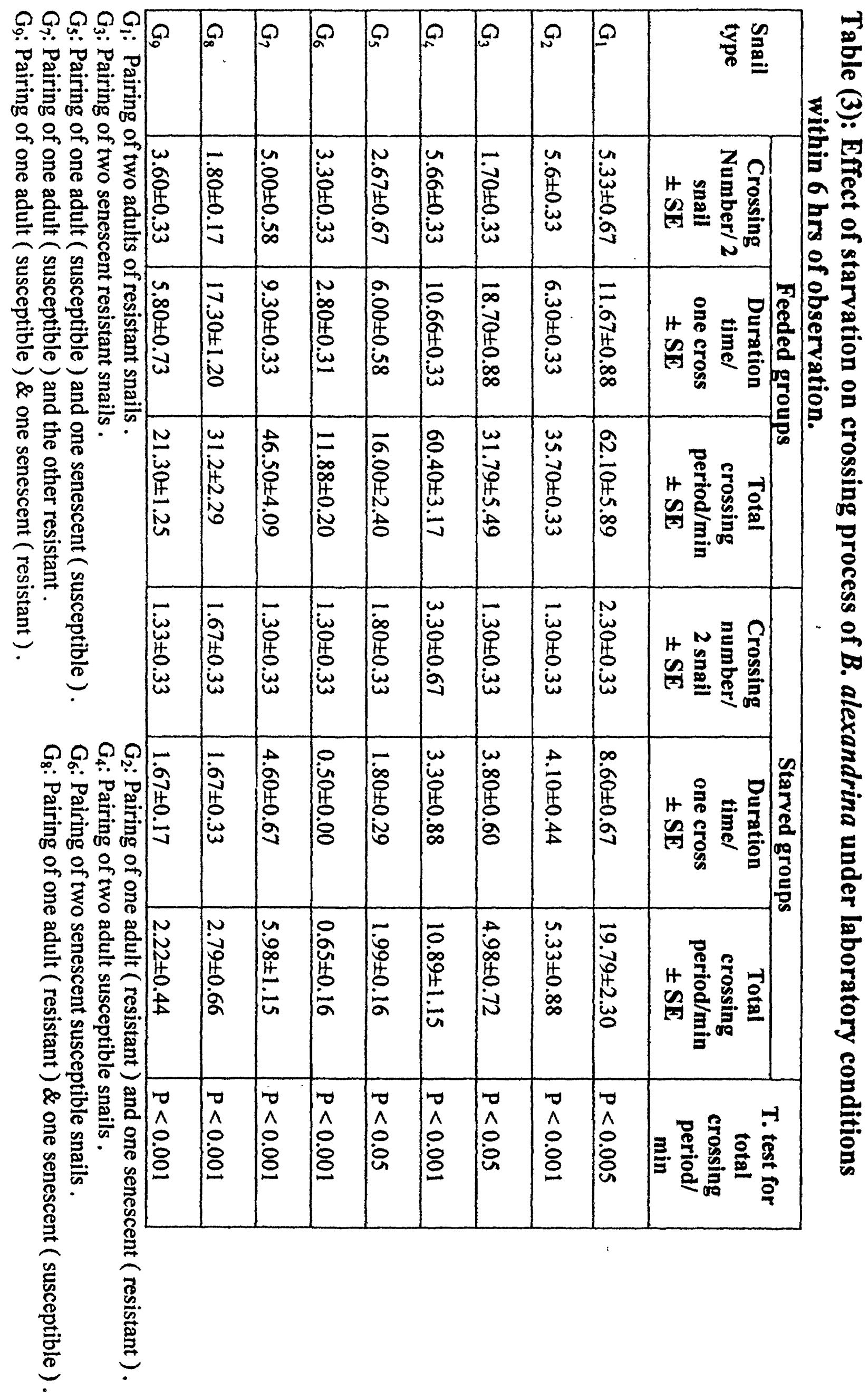




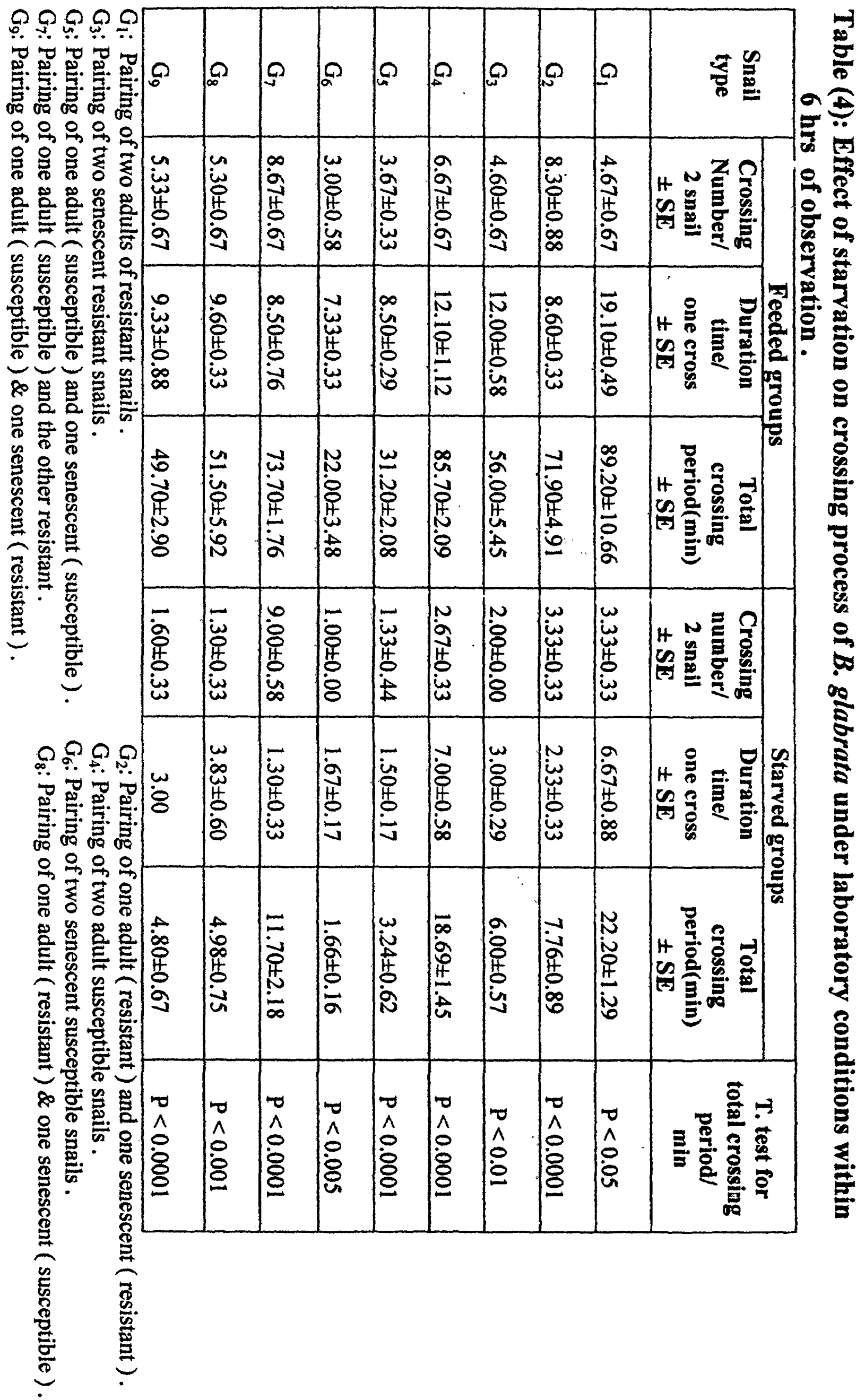




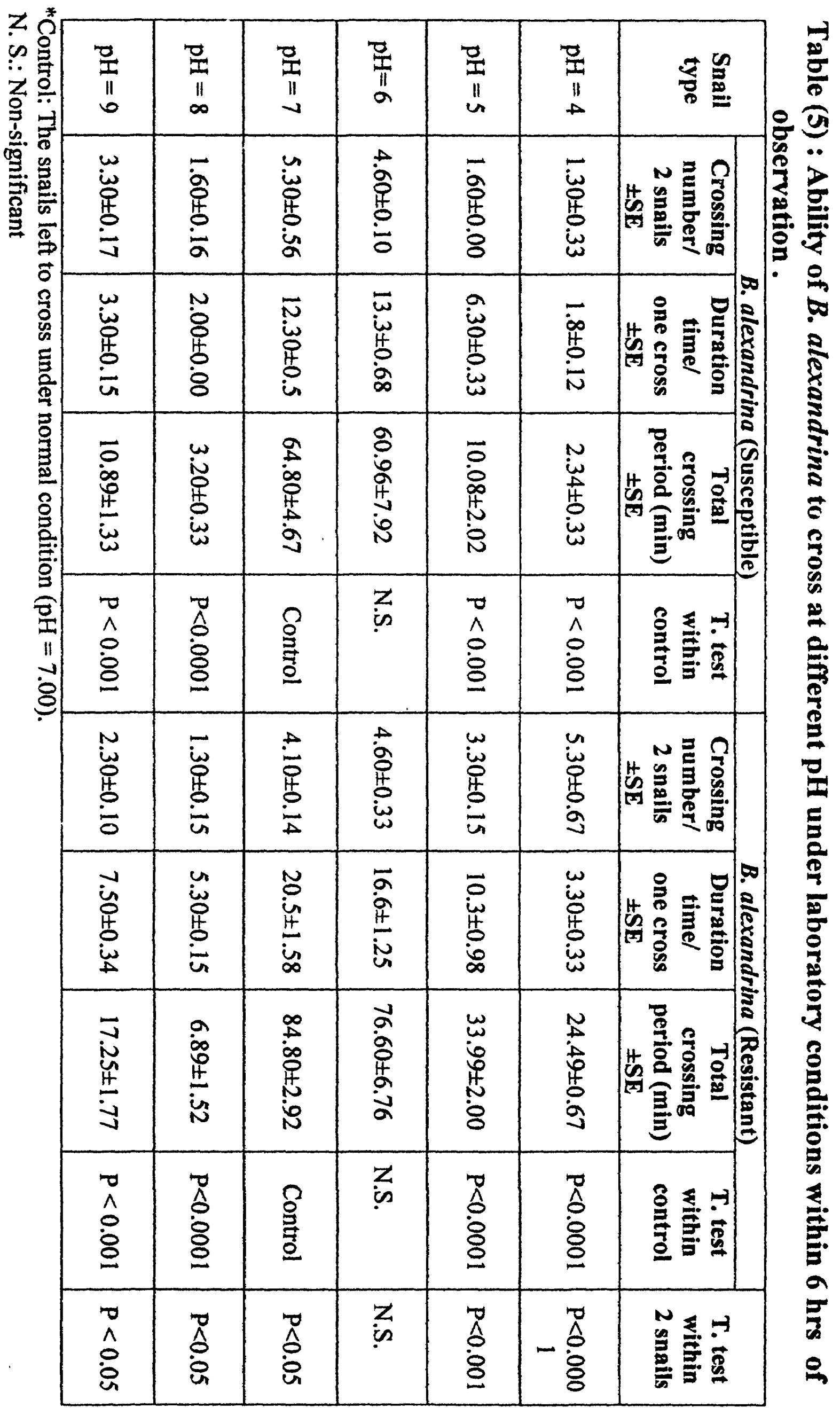




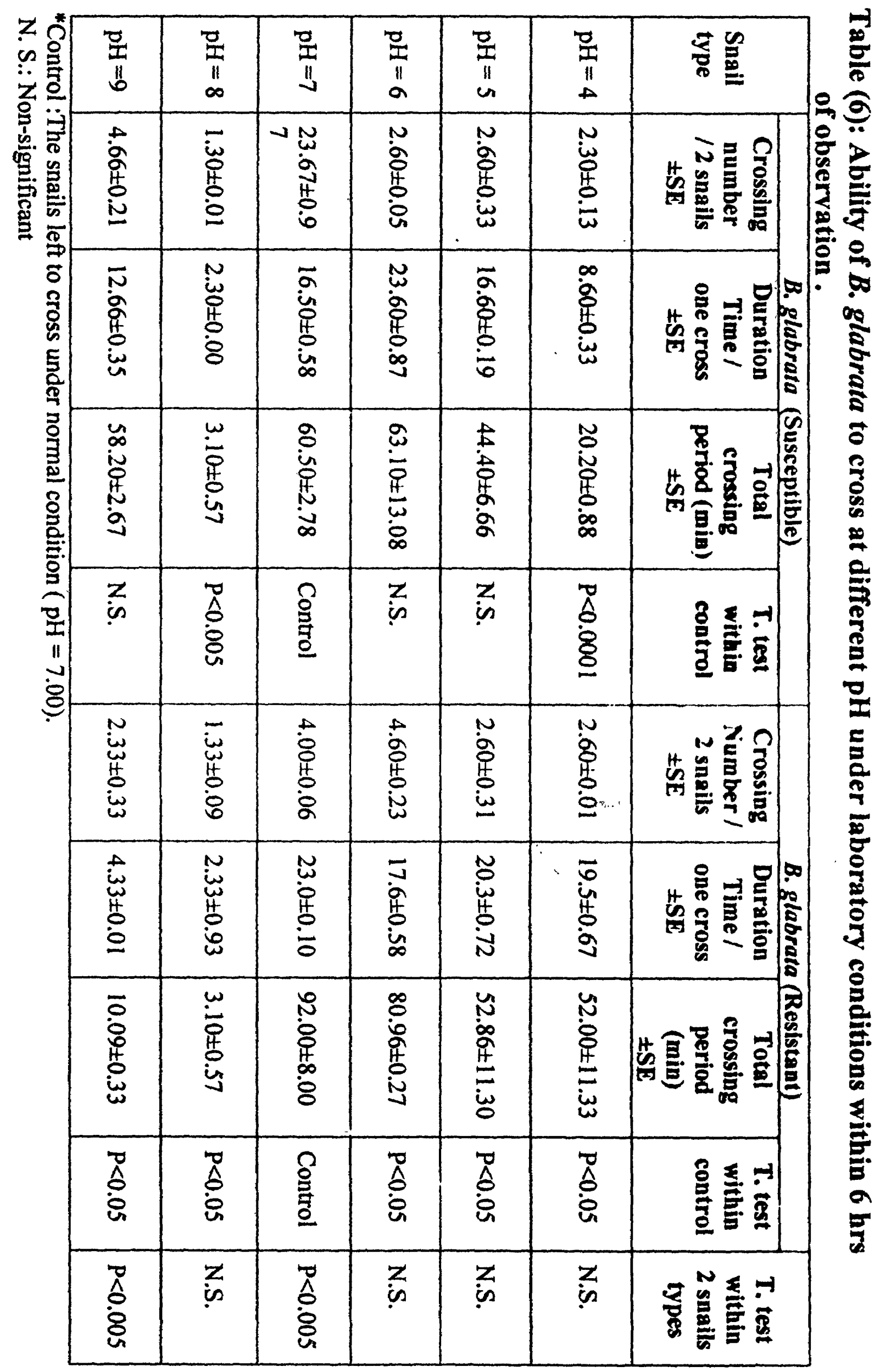




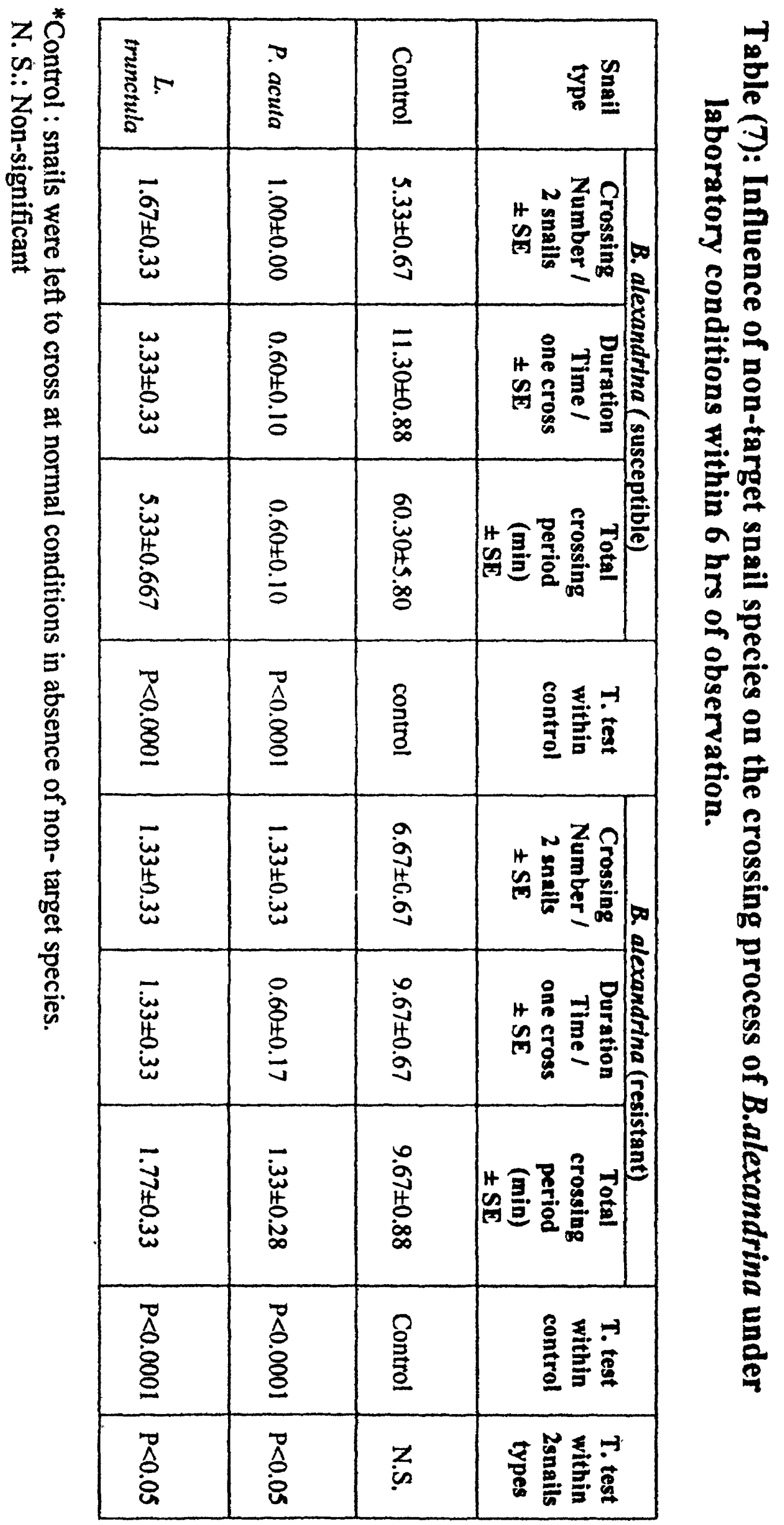




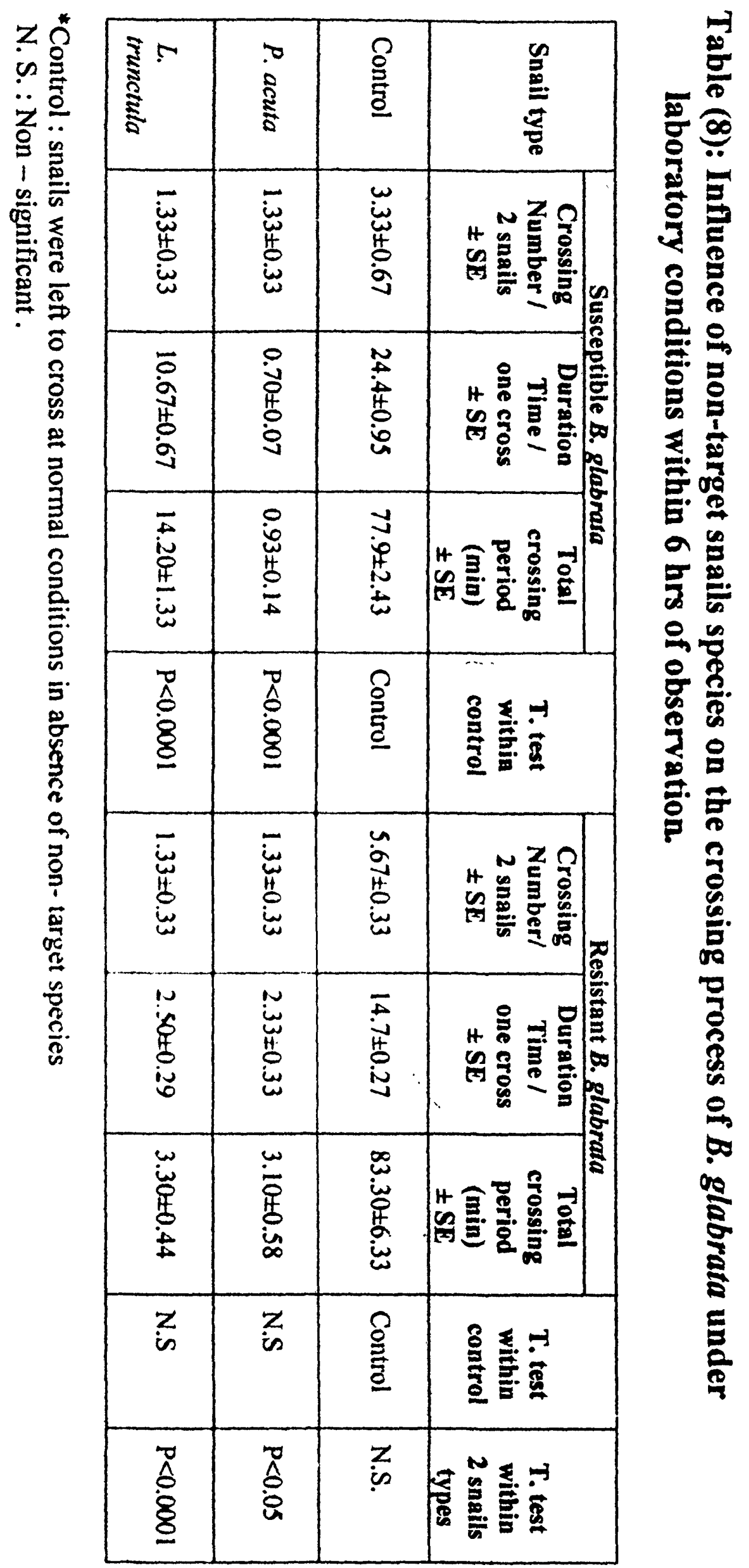


